\title{
Relationship between circulating levels of angiotensin-converting enzyme 2-angiotensin-(1-7)-MAS axis and coronary heart disease
}

\author{
Xiaomin Zhou ${ }^{1,2} \cdot$ Ping Zhang ${ }^{1,2} \cdot$ Tao Liang $^{1} \cdot$ Yongyue Chen ${ }^{1,3} \cdot$ Dan Liu $^{1,4} \cdot$ Huimin $^{1} u^{1,2,5}$ (1)
}

Received: 21 January 2019 / Accepted: 19 July 2019 / Published online: 29 July 2019

(c) Springer Japan KK, part of Springer Nature 2019

\begin{abstract}
As a counter-regulatory arm of the renin angiotensin system (RAS), the angiotensin-converting enzyme 2-angiotensin-(1-7)MAS axis (ACE2-Ang-(1-7)-MAS axis) plays a protective role in cardiovascular diseases. However, the link between circulating levels of ACE2-Ang-(1-7)-Mas axis and coronary atherosclerosis in humans is not determined. The object of present study was to investigate the association of circulating levels of ACE2, Ang-(1-7) and Ang-(1-9) with coronary heart disease (CHD) defined by coronary angiography (CAG). 275 patients who were referred to CAG for the evaluation of suspected CHD were enrolled and divided into two groups: CHD group (diameter narrowing $\geq 50 \%, n=218$ ) and non-CHD group (diameter narrowing $<50 \%, n=57$ ). Circulating ACE2, Ang-(1-7) and Ang-(1-9) levels were detected by enzyme-linked immunosorbent assay (ELISA). In females, circulating ACE2 levels were higher in the CHD group than in the non-CHD group (5617.16 $\pm 5206.67 \mathrm{vs.} 3124.06 \pm 3005.36 \mathrm{pg} / \mathrm{ml}, P=0.009)$, and subgroup analysis showed the significant differences in ACE2 levels between the two groups only exist in patients with multi-vessel lesions $(P=0.009)$. In multivariate logistic regression, compared with the people in the lowest ACE2 quartile, those in the highest quartile had an OR of 4.33 (95\% CI 1.20-15.61) for the CHD ( $P$ for trend $=0.025$ ), the OR was 5.94 (95\% CI 1.08-32.51) for the third ACE2 quartile and 9.58 (95\% CI 1.61-56.95) for the highest ACE2 quartile after adjusting for potential confounders $(P$ for trend $=0.022)$. However, circulating Ang-(1-7) and Ang-(1-9) levels had no significant differences between the two groups. In males, there were no significant differences in the levels of ACE2-Ang-(1-7)-MAS axis between two groups. Together, circulating ACE2 levels, but not Ang-(1-7) and Ang-(1-9) levels, significantly increased in female CHD group when compared with non-CHD group, increased ACE2 was independently associated with CHD in female and in patients with multi-vessel lesions even after adjusting for the confounding factors, indicating that ACE2 may participate as a compensatory mechanism in CHD.
\end{abstract}

Keywords Coronary heart disease $\cdot$ Angiotensin-converting enzyme $2 \cdot$ Angiotensin-(1-7) $\cdot$ Angiotensin-(1-9) $\cdot$ Renin angiotensin system

\section{Introduction}

Xiaomin Zhou and Ping Zhang contributed equally to this work.

Electronic supplementary material The online version of this article (https://doi.org/10.1007/s00380-019-01478-y) contains supplementary material, which is available to authorized users.

Huimin Yu

yuhm138@163.com

1 Department of Cardiology, Guangdong Cardiovascular Institute, Guangdong Provincial People's Hospital, Guangdong Academy of Medical Sciences, Guangzhou, China

2 The Second School of Clinical Medicine, Southern Medical University, Guangzhou, China
Dysregulation of the renin angiotensin system (RAS) is considered a major factor in the development of cardiovascular pathologies [1]. Within the RAS, the angiotensinconverting enzyme (ACE) converts angiotensin (Ang) I to

3 Department of Cardiology, Shantou Central Hospital and Affiliated Shantou Hospital of SunYat-Sen University, Shantou, China

4 Department of Cardiology, Hospital of Panyu District, Guangzhou, China

5 Department of Cardiology, Guangdong General Hospital's Nanhai Hospital, Foshan, China 
the vasoconstrictor Ang II [2], which regulates salt/water homeostasis and vasoconstriction, modulates blood pressure, is also implicated in inflammation, endothelial dysfunction, and oxidative stress [3]. A counter-regulatory arm of the RAS is now known to exist. ACE2 is a novel ACE homolog that binds to the Mas receptor (MasR) and metabolizes Ang I and Ang II into the inactive Ang-(1-9) as well as into the Ang-(1-7), in addition, Ang-(1-7) can be also directly generated from Ang-(1-9) through cleavage of ACE [4-6]. The generated Ang-(1-7) exerts a variety of cardioprotective effects, many of which are opposite to those attributed to Ang II $[7,8]$.

ACE2 is widely distributed [9], and is expressed in abundance in the heart, blood vessels, and kidney [2], where it exerts important actions in cardiac function and blood pressure. Ang-(1-7) is mainly formed by the ACE2, it opposes many Ang II-stimulated actions. Ang-(1-9) has also shown beneficial biological effects via Ang II type 2 receptors (AT2R) that result in cardioprotection [10, 11]. Several lines of evidence have showed the role of ACE2Ang-(1-7)-Mas axis in atherosclerosis. ACE2 protein is expressed in endothelial cells, smooth muscle cells and macrophages in aortic and coronary atherosclerotic lesions $[12,13]$. ACE2 overexpression significantly inhibits early atherosclerotic lesions development both in human endothelial cells in vitro and in apoE-deficient mice in vivo [14]. A similar anti-atherosclerotic effect of ACE2 was seen in a rabbit atherosclerosis model [15]. In addition, ACE2 overexpression attenuated the progression of lesions and stabilized atherosclerotic plaques in rabbits, which were formed by endothelial injury and atherogenic diet [16]. Conversely, genetic ACE2 deficiency significantly increased accumulation of atherosclerotic plaque via upregulation of putative mediators of atherogenesis and enhancing responsiveness to proinflammatory stimuli [17]. A differential regulation of ACE2 activity during the progression of atherosclerosis has been reported that enzymatic activity of ACE2 was lower in the stable advanced atherosclerotic lesions, compared to early and ruptured atherosclerotic lesions [12]. Similar to ACE2, the atheroprotection of Ang-(1-7) has been shown in many previous studies. The levels of Ang-(1-7) were elevated in late atherosclerotic plaques in ApoE-knockout mice, and the endogenous activated Ang-(1-7) played a protective effect against atherosclerotic plaques instability [18]. Longterm Ang-(1-7) treatment caused a reduction in lesion progression in a mouse model of atherosclerosis and improvement in endothelial function [19]. Moreover, Ang-(1-7) dose dependently inhibited early atherosclerotic lesions via suppressing vascular smooth muscle cells proliferation and migration, and a large dose of Ang-(1-7) enhanced plaque stability via inhibiting plaque inflammation [20].

As is mentioned above, the role of ACE2-Ang-(1-7)Mas axis in the pathogenesis of atherosclerosis has been investigated with use of various animal models, but most of the studies have focused on ACE2, not much is known regarding the role of Ang-(1-7) and Ang-(1-9) in coronary atherosclerosis, there have been no clinical studies to confirm the link between circulating levels of ACE2-Ang-(1-7)Mas axis and coronary atherosclerosis in humans. Thus, the aim of the present study was to examine the association between circulating levels of ACE2, Ang-(1-7) and Ang(1-9) and coronary heart disease (CHD) defined by coronary angiography (CAG).

\section{Materials and methods}

\section{Study population}

275 consecutive patients who underwent CAG for the evaluation of suspected CHD in the Cardiology Department of Guangdong Provincial People's Hospital were enrolled in the present study. CHD was defined as significant coronary stenosis $(\geq 50 \%)$ in at least one major coronary artery following the World Health Organization (WHO) criteria, it was assessed using CAG or if a subject showed prior percutaneous or surgical coronary revascularization. According to this, all subjects were divided into two groups: CHD group (diameter narrowing $\geq 50 \%, n=218$ ) and non-CHD group (diameter narrowing $<50 \%, n=57$ ). Major exclusion criteria included: congestive heart failure; clinically important cardiac arrhythmia; valvular heart disease; ongoing systemic inflammatory diseases; renal or hepatic dysfunction; malignant disease; the use of drugs that may influence RAS hormone levels, such as direct renin inhibitors (DRIs), ACE inhibitors (ACEIs), Ang II receptor blockers (ARBs), or aldosterone antagonists (AAs); pregnancy or lactation in women; patient's unwillingness to participate in the survey.

\section{Angiographic analysis}

All patients underwent CAG via femoral or radial artery with a standard method, and the angiograms were evaluated by two experienced cardiologists who were blinded to all other data. The severity of CHD was assessed by the number of stenotic coronary vessels. Single-vessel disease was defined as a $\geq 50 \%$ stenosis in only one major epicardial artery or an important branch of a major epicardial coronary artery. Multi-vessel coronary disease means the presence of $a \geq 50 \%$ stenosis in two or more major epicardial arteries or left main coronary artery. The SYNTAX scoring system was utilized to quantify the complexity of CHD, each coronary lesion with a diameter stenosis $\geq 50 \%$ in vessels $\geq 1.5 \mathrm{~mm}$ was scored, using the online SYNTAX score calculator (Version 2.28, www.syntaxscore.com). With the cutoffs used in 
the current US/European guidelines, patients with low lesion complexity had SYNTAX scores $\leq 22$, intermediate lesion complexity was defined as a SYNTAX score 23-32, and high lesion complexity was defined as a SYNTAX score $\geq 33$ [21].

\section{Clinical and laboratory assessments}

Detailed demographics and anthropometrics parameters (family, medical and drug histories) of each study object were recorded. Body mass index (BMI) was calculated as the body weight $(\mathrm{kg})$ divided by the square of the height $\left(\mathrm{m}^{2}\right)$. Blood pressure and heart rate (HR) were measured by trained doctors or nurses using a sphygmomanometer after the patient had rested for at least $10 \mathrm{~min}$ and were determined as the mean of 3 measurements taken 1 min apart. Diabetes was defined as fasting blood glucose (FBG) $\geq 7 \mathrm{mmol} / \mathrm{L}$, or 2-h postload glucose level $\geq 11.1 \mathrm{mmol} / \mathrm{L}$ and/or glycated hemoglobin $(\mathrm{HbA} 1 \mathrm{c}) \geq 6.5 \%$ according to WHO criteria. Biochemical parameters such as serum potassium, sodium, chloride, creatinine, blood urea nitrogen (BUN), FBG, total cholesterol (TC), triglyceride (TG), high-density lipoprotein cholesterol (HDL-C), and low-density lipoprotein cholesterol (LDL-C) were measured using standard procedures in the hospital clinical laboratory. The circulating levels of ACE2-Ang-(1-7)-MAS axis were measured using commercial enzyme-linked immunosorbent assay (ELISA) kits (Cloud-Clone Corp, Houston). The ELISA for measurement of ACE2 employed the sandwich enzyme immunoassay technique and the ELISA for measurement of Ang-(1-7) and Ang-(1-9) employed the competitive inhibition enzyme immunoassay. According to the kit instructions, the reaction system and standard curve were established. The absorbance of each sample was measured by enzyme-linked immunosorbent analyzer. The content of ACE2, Ang-(1-7) and Ang(1-9) were calculated in accordance with the standard curve (for plasma measurement, blood was collected within $48 \mathrm{~h}$ ).

\section{Statistical analysis}

All analyses were performed using IBM SPSS statistical software (version 25.0; IBM Corp, Armonk, NY). Continuous variables were expressed as means \pm standard deviation (SD) or median (interquartile range) and categorical variables as percentages. Chi square test and a standard one-way analysis of variance (ANOVA) test were used for comparisons of categorical and continuous variables, respectively. Univariable and multivariate logistic regression analyses were performed to determine factors associated with CHD. We divided the distribution of ACE2 parameters into quartiles, the odds ratio (OR) and $95 \%$ confidence interval (CI) were calculated in relation to each quartile increase of ACE2 levels. The univariable associations between 16 covariates and CHD are indicated in Supplementary Table 3. Variables with a $P$ value $<0.10$ in univariate analysis were entered into multivariate analysis. Previous studies reported that diabetes was closely associated with CHD [22, 23], thus diabetes was entered into multivariate analysis. OR were estimated using several logistic regression models with progressive adjustment: model 1 was unadjusted, model 2 was adjusted for age and diabetes, model 3 was further adjusted for SBP, sodium, FBG, HDL-C. We considered a $P$ value less than 0.05 as significant for all test.

\section{Results}

Clinical and biochemical characteristics of the study subjects including 218 angiography confirmed CHD patients and 57 non-CHD patients are presented in Table 1. Subjects who had CHD tended to be men and older, and more of them had higher potassium, FBG levels than those who did not develop CHD. The serum sodium, HDL-C levels of CHD patients were lower than that of non-CHD patients. The other clinical characteristics were comparable between CHD patients and non-CHD patients.

Table 1 Baseline characteristics of the study population

\begin{tabular}{llll}
\hline Variables & CHD (218) & Non-CHD (57) & $P$ value \\
\hline Age (years) & $65.10 \pm 9.29$ & $60.19 \pm 9.89$ & 0.001 \\
Male $(\%)$ & $54.59 \%$ & $31.58 \%$ & 0.002 \\
BMI $\left(\mathrm{kg} / \mathrm{m}^{2}\right)$ & $23.91 \pm 3.18$ & $23.69 \pm 3.42$ & 0.659 \\
HR (beats/min) & $75.30 \pm 12.17$ & $76.21 \pm 12.42$ & 0.619 \\
SBP $(\mathrm{mmHg})$ & $142.23 \pm 21.59$ & $136.47 \pm 22.04$ & 0.079 \\
DBP $(\mathrm{mmHg})$ & $78.61 \pm 10.85$ & $80.00 \pm 15.20$ & 0.527 \\
Potassium $(\mathrm{mmol} / \mathrm{L})$ & $3.73 \pm 0.44$ & $3.63 \pm 0.28$ & 0.043 \\
Sodium $(\mathrm{mmol} / \mathrm{L})$ & $139.02 \pm 2.67$ & $140.08 \pm 2.07$ & 0.006 \\
Chloride $(\mathrm{mmol} / \mathrm{L})$ & $103.80 \pm 7.32$ & $105.37 \pm 3.34$ & 0.120 \\
Creatinine $(\mu \mathrm{mol} / \mathrm{L})$ & $86.69 \pm 42.85$ & $77.52 \pm 28.75$ & 0.131 \\
BUN $(\mathrm{mmol} / \mathrm{L})$ & $5.41 \pm 3.33$ & $5.28 \pm 2.20$ & 0.778 \\
FBG $(\mathrm{mmol} / \mathrm{L})$ & $6.84 \pm 2.51$ & $6.13 \pm 1.81$ & 0.018 \\
Triglyceride $(\mathrm{mmol} / \mathrm{L})$ & $1.68 \pm 1.01$ & $1.78 \pm 1.51$ & 0.559 \\
Total cholesterol & $4.35 \pm 1.24$ & $4.52 \pm 0.97$ & 0.338 \\
$\quad(\mathrm{mmol} / \mathrm{L})$ & & & \\
LDL-C (mmol/L) & $2.52 \pm 1.01$ & $2.49 \pm 0.80$ & 0.850 \\
HDL-C (mmol/L) & $1.02 \pm 0.27$ & $1.12 \pm 0.23$ & 0.011 \\
Diabetes $(\%)$ & $43.31 \%$ & $32.35 \%$ & 0.240 \\
\hline
\end{tabular}

Values are expressed as mean \pm standard deviation (SD) or percentages

$B M I$ body mass index, $H R$ heart rate, $S B P$ systolic blood pressure, $D B P$ diastolic blood pressure, $B U N$ blood urea nitrogen, $F B G$ fasting blood glucose, $L D L-C$ low-density lipoprotein cholesterol, $H D L-C$ high-density lipoprotein cholesterol 
As shown in Fig. 1, males had significantly higher ACE2 (male vs. female; $6612.64 \pm 4069.48$ vs. $4907.74 \pm 4808.85 \mathrm{pg} / \mathrm{ml}, P=0.003)$, Ang-(1-7) (male vs. female; $1138.44 \pm 1023.23$ vs. $804.13 \pm 633.98 \mathrm{pg} /$ $\mathrm{ml}, P=0.002)$ activities, while lower Ang-(1-9) (male vs. female; $47.28 \pm 46.29$ vs. $63.16 \pm 63.89 \mathrm{pg} / \mathrm{ml}, P=0.021$ ) levels than females. Thus, further between-group comparisons were performed separately for males and females. The circulating ACE2 levels were increased in female CHD patients when compared to non-CHD patients $(5617.16 \pm 5206.67$ vs. $3124.06 \pm 3005.36 \mathrm{pg} / \mathrm{ml}, P=0.009$; Fig. 2a), while Ang-(1-7) and Ang-(1-9) levels had no significant differences between two groups (Fig. 2b, c). There
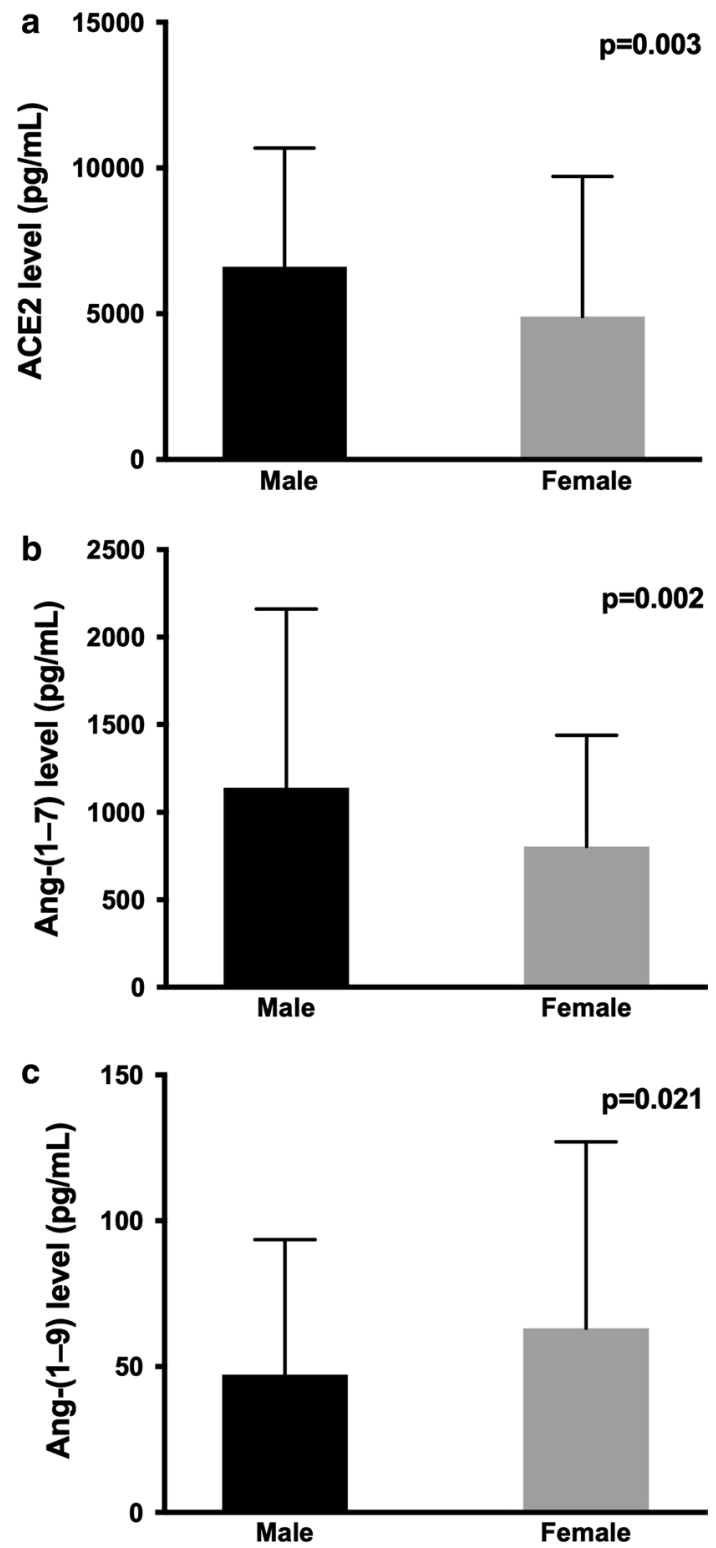

Fig. 1 Gender differences in circulating levels of ACE2-Ang-(1-7)MAS axis
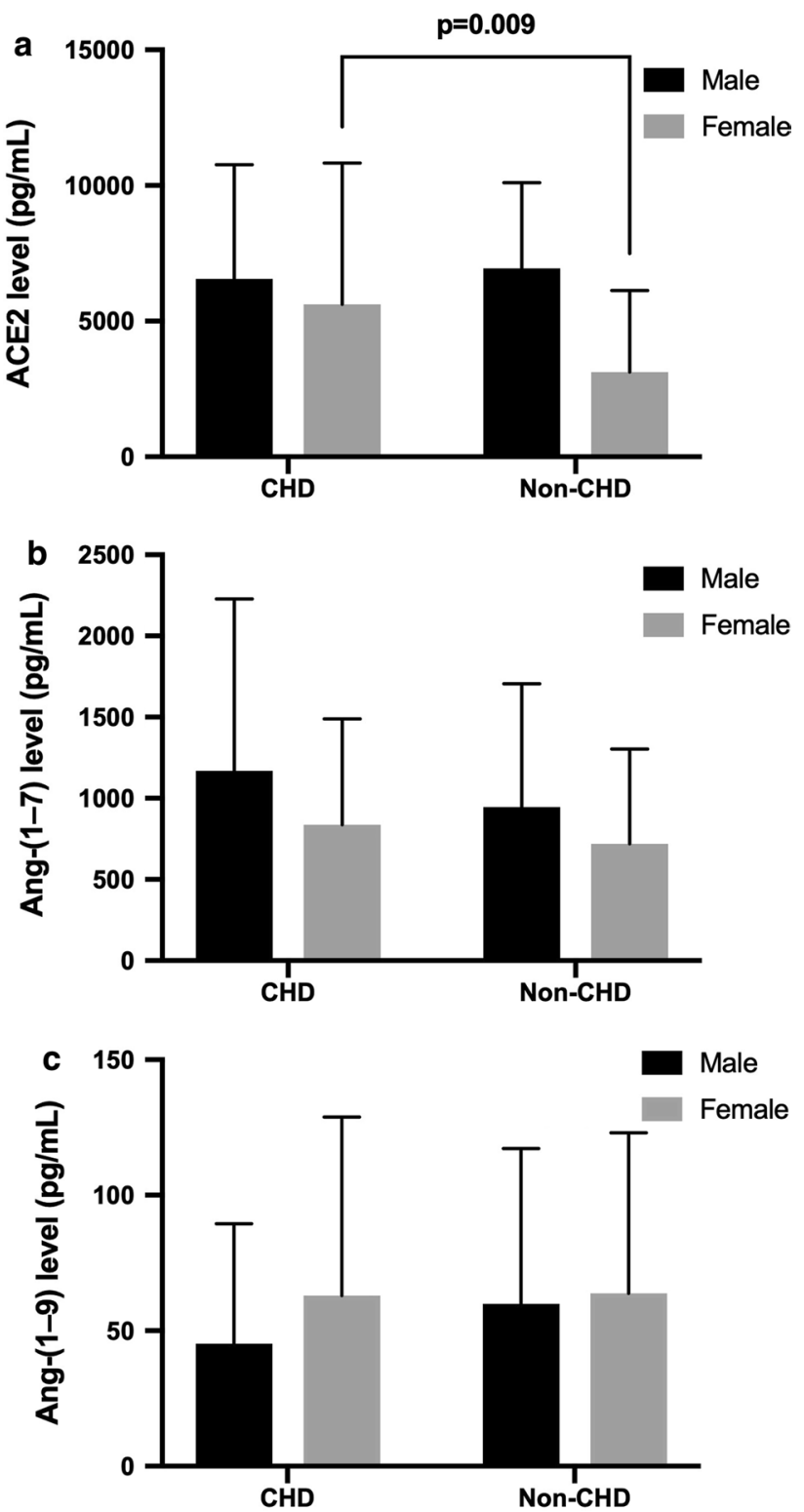

Fig. 2 Comparison of circulating ACE2, Ang-(1-7) and Ang-(1-9) levels between $\mathrm{CHD}$ and non-CHD groups

were also no significant differences of circulating ACE2, Ang-(1-7) and Ang-(1-9) levels between male patients with and without CHD (Fig. 2).

The circulating ACE2 levels were divided into quartile categories, then calculated the OR and 95\% CI using multiple logistic regression analysis to evaluate predictors of CHD for study population (Table 2). The quartiles of ACE2 were significantly associated with CHD in female ( $P$ for trend $=0.025$ ), compared with the people in the lowest ACE2 quartile, those in the highest quartile had an OR of 4.33 (95\% CI 1.20-15.61) for the CHD. After adjustment for age, diabetes, SBP, sodium, FBG, HDL-C (model 3), the OR was 5.94 (95\% CI 1.08-32.51) for the 
Table 2 Predictors of increased ACE2 levels for CHD in female by multiple logistic regression analysis

\begin{tabular}{llllll}
\hline & \multicolumn{2}{l}{ Quartiles of ACE2, OR $(95 \%$ CI } & \multirow{2}{*}{$P$ value for trend } \\
\cline { 2 - 5 } & Q1 & Q2 & Q3 & Q4 \\
\hline Model 1: crude & 1.00 & $1.40(0.49-4.00)$ & $1.70(0.59-4.93)$ & $4.33(1.20-15.61)$ & 0.025 \\
$P$ value & & 0.530 & 0.325 & 0.025 & \\
Model 2 & 1.00 & $6.97(0.88-54.88)$ & $4.81(0.90-25.81)$ & $7.36(1.30-41.79)$ & 0.018 \\
$P$ value & & 0.065 & 0.067 & 0.024 & \\
Model 3 & 1.00 & $6.25(0.84-46.57)$ & $5.94(1.08-32.51)$ & $9.58(1.61-56.95)$ & 0.022 \\
$P$ value & & 0.074 & 0.040 & 0.013 & \\
\hline
\end{tabular}

Model 1 crude, Model 2 adjusted age, diabetes, Model 3 adjusted for model 2, SBP, sodium, FBG, HDL-C

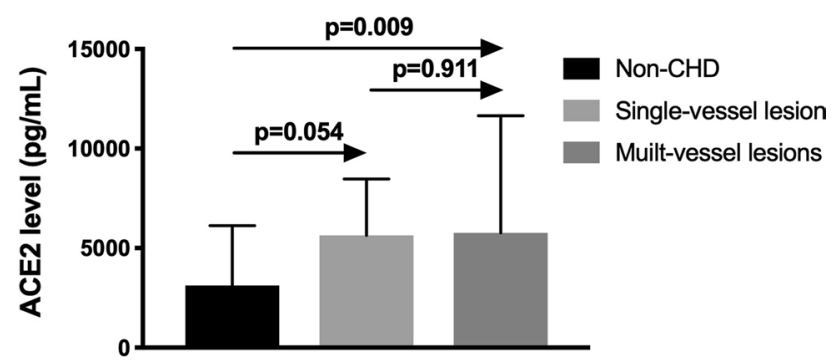

Fig. 3 The circulating levels of ACE2 in the non-CHD, single-vessel lesion and multi-vessel lesions groups

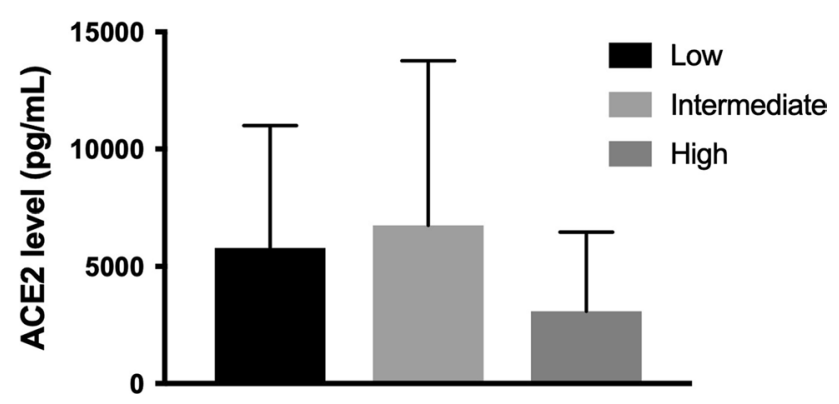

Fig. 4 The circulating levels of ACE2 in the low SYNTAX score, intermediate SYNTAX score and high SYNTAX score groups

third ACE2 quartile and 9.58 (95\% CI 1.61-56.95) for the highest ACE2 quartile $(P$ for trend $=0.022$ ).

The study subjects were divided into three groups according to the number of diseased coronary arteries (non-CHD, single vessel and multi-vessels), then stratified into three groups based on SYNTAX score (low score $\leq 22$, intermediate score $23-32$, and high score $\geq 33$ ) $[24,25]$. Significant difference was found between the multi-vessel lesions group and the non-CHD group $(P=0.009)$, but not in other groups $(P>0.05)$ (Fig. 3). Circulating ACE2 level had no correlation with the complexity of atherosclerosis assessed by SYNTAX score $(P=0.159)$ (Fig. 4).

\section{Discussion}

This study characterizes for the first time the levels of ACE2-Ang-(1-7)-MAS axis in patients with CHD. We demonstrated gender differences in circulating levels of ACE2Ang-(1-7)-MAS axis, further we performed sex-specific analyses. In females, circulating ACE2 levels were higher in the CHD group than in the non-CHD group, and multivariate logistic regression analyses showed that ACE2 was independently associated with CHD. However, circulating Ang-(1-7) and Ang-(1-9) levels were comparable between two groups. In males, the levels of ACE2-Ang-(1-7)-MAS axis had no significant differences between CHD patients and non-CHD patients.

The ACE2 gene is located on the $\mathrm{X}$ chromosome, ACE2 converts Ang I and Ang II into Ang-(1-9) and Ang-(1-7), and it is reasonable that there is gender difference in the ACE2-Ang-(1-7)-MAS axis. Studies in healthy individuals and in subjects with type 1 diabetes [26] and renal disease [27] demonstrated that males had a trend for higher ACE2 activities than females. Our result was in accordance with previous findings with higher serum ACE2 activities in males than in females. Renal cortical Ang-(1-7) levels were higher in female spontaneously hypertensive rats compared with male rats $[28,29]$, and a study involving 24 healthy subjects reported women exhibit higher plasma concentrations of Ang-(1-7) compared with men [30]. In contrast, results of a previous study involving 93 healthy subjects showed men have significantly higher circulating Ang-(1-7) levels than women [31]. We first examine the influence of gender on circulating levels of Ang-(1-7) in patients with and without CHD, and our results showed the levels of Ang(1-7) in men are higher than that in women, the higher levels of Ang-(1-7) in men might be linked to increases in ACE2 which could promote Ang-(1-7) formation from Ang II. This is one of the first studies to demonstrate the circulating levels of Ang-(1-9) are higher in females, we speculated that higher Ang-(1-9) levels in females may result in the increased activities of Ang I or other components which directly convert Ang I to Ang-(1-9). Therefore, although there are some inconsistent results, gender difference in 
the ACE2-Ang-(1-7)-MAS axis does exist, which may be mediated, in part, by sex hormones. For example, estrogen has been demonstrated to associate with nonclassical RAS components including ACE2, Ang-(1-7) and MasR activity [32-34]. In addition, gender differences in the presentation, prevalence and clinical outcomes of CHD are known to exist [35], thus we performed sex-specific analyses subsequently. Further larger population studies are needed to investigate and determine whether the associations of this axis with CHD vary according to gender.

A cleavage of the catalytically active ectodomain of ACE2 results in a smaller protein fragment found in plasma, serum and urine, is known as soluble ACE2 [7]. Circulating ACE2 activity has been considered to be a marker of cardiovascular disease (CVD), with low levels in healthy individuals, and increased levels in those with CVD such as hypertension [36], heart failure [37] and myocardial infarction [38]. The major finding of the present study was that circulating ACE2 levels were increased in female angiographically proven CHD patients, suggesting ACE2 activity may serves as a novel marker of CHD in women. In a study involving 859 subjects with type 1 diabetes, circulating ACE2 levels were significantly higher in those who had a history of CHD [26], ACE2 seems to combat the adverse effects of activated RAS and, therefore, may be a compensatory mechanism in coronary atherosclerosis. Previous studies have shown that the expression of cardiac ACE2 was increased after myocardial infarction (MI) [39-42], the circulating ACE2 activities were also significantly increased in MI patients [43, 44] and animal models [38]. Our results suggested that even though without acute myocardial injury there is an increase in circulating ACE2, which may reflect coronary underlying atherosclerosis rather than MI [45].

However, the association of ACE2 with CHD is not found in men. Sex dimorphism of CHD has been observed in the prevalence and the onset age of CHD. Estrogen is thought to have beneficial effects on atherosclerotic plaque progression, vasodilation, and blood pressure [46]. Prior to menopause, women have relatively more protection against CHD compared with men of the same age range, and the onset age of CHD in women is typically 10 years later than that in men [47]. Therefore, it is generally considered that male is a risk factor for CHD, but interestingly, the serum ACE2 levels were associated with CHD only in women in our study. Several mechanisms may explain why serum ACE2 has a greater relative risk for CHD in women than in men. First, our study showed that differences in the baseline levels of age, SBP, sodium, FBG, and HDL-C among participants with and without CHD were significantly greater in women than in men (Supplementary Table 1 and Table 2). The sex difference in the CHD risk related to the ACE2 level may be mediated in part by differences in the levels of other cardiovascular risk factors. Moreover, women have been found to have a longer time from symptom onset until diagnosis and intervention, are less likely to receive proven efficacious therapies ( $\beta$-blockers, aspirin, statins, thrombolytics), are less likely to be referred for invasive testing and coronary artery bypass grafting [46], the treatment bias that favors men may cause the excess relative risk of CHD in women with higher ACE2 levels.

After adjusting for the confounding factors, the risk of developing CHD remained significantly higher in the highest circulating ACE2 level quartile group than in the lowest quartile group in woman. We indicated, for the first time, that circulating ACE2 level independently predicted the development of CHD in woman subjects. Further, within-CHD group analysis showed that ACE2 in the multi-vessel lesions group but not in the singlevessel lesion group was significantly higher than that in the non-CHD group. These results indicate that ACE2 is independently associated with CHD in female patients and is connected with multi-vessel lesions. The SYNTAX score has been used to score complexity of CHD, there is no significant correlation between the circulating ACE2 levels and the SYNTAX score in CHD patients found in our study, suggesting circulating ACE2 activity cannot act as the marker for evaluating the complexity of CHD. In summary, our findings demonstrated that increased ACE2 was independently associated with CHD in female and in patients with multi-vessel lesions even after adjusting for the confounding factors, these results reinforced the important counter-regulatory role of ACE2 in coronary atherosclerosis. Thus, modulation of ACE2 could offer a future therapeutic option in patients with atherosclerotic disease.

ACE2 undergoes shedding to release the catalytically active ectodomain into the extracellular milieu, this process results in ACE2 that can be detected in the circulation. The shedding of the membrane-bound ACE2 is stimulated by a disintegrin and metalloproteinase, ADAM17, which is known as tumor necrosis factor- $\alpha$-converting enzyme (TACE) [48]. There may be an aberrant neo-expression of ACE2 in endothelial cells under pathologic conditions [49], in certain conditions such as MI, kidney disease or diabetes, this abnormally expressed endothelial protein could be shed into the circulation thus could be the source of increased circulating ACE2 activity [50]. A previous study showed the tissue ACE2 activity in human-ruptured atherosclerotic lesions is increased when compared with that in stable advanced atherosclerotic lesions [12]. We suggested that circulating ACE2 levels were higher in female CHD patients than those without CHD, the circulating ACE2 level was associated with tissue ACE2 expression. Our results support that the increase in circulating ACE2 level reflects increased tissue ACE2 synthesis from mRNA and increased ACE2 shedding of the protein, and further studies 
that simultaneously measure tissue and circulating ACE2 activity are needed.

As is mentioned above, Ang-(1-7) and Ang-(1-9) have been proposed to be important mediators in cardioprotection [51]. A series of studies demonstrated that both plasma and myocardial tissue levels of Ang-(1-7) significantly increased in myocardial infarction [41, 52]. In contrast, another study indicated that the circulating levels of Ang-(1-9), but not Ang-(1-7) levels, increased 1 week after myocardial infarction [38]. This latter observation is consistent with our findings on circulating Ang-(1-7) levels, which increased in the CHD patients, but the difference was not significant. Ang(1-7) has been proved as a protective factor against atherosclerosis because of its actions that are mainly opposite to those of Ang II, including antifibrotic and antitropic actions in heart, vasodilation and antiproliferation effects in blood vessels [53]. It has been demonstrated that the plasma levels of Ang-(1-7) were not significantly changed in patients with noncritical coronary atherosclerosis, moreover, for patients with severe coronary atherosclerosis, Ang-(1-7) levels were elevated [54]. Thus, we believe that Ang-(1-7) might as a compensatory mechanism in the development of human atherosclerosis, more clinical strategies to evaluate circulating Ang-(1-7) in coronary atherosclerosis are needed to confirm this conclusion. Our data suggested no change in the levels of Ang-(1-9) between the two groups. Little is known regarding the role of Ang-(1-9), and it may act as an intermediate involved in the formation of Ang-(1-7) from Ang I by ACE2. Whether Ang-(1-9) itself has a direct biological effect on cardiac or actions through the generation of different metabolites is still an open question. This is one of the first studies to demonstrate the levels of Ang-(1-7) and Ang-(1-9) are not parallel with the increase of serum ACE2 levels in patients suspected with CHD, suggesting increased ACE2 activity might directly affect atherosclerosis progress rather than induce more conversion from Ang II to Ang-(1-7) or Ang I to Ang-(1-9).

Several limitations should be considered. First, this was single-center study involving a relatively small number of patients, and further studies with a larger sample size needs to be performed. Second, the patients with CHD had a higher percentage compared with the non-CHD groups, which led to the difference in the numbers between the two groups. Third, this was a cross-sectional study, which limited the conclusions about causality of our associations, longterm follow-up may strengthen our conclusion. Finally, we did not simultaneously measured tissue and circulating levels of ACE2-Ang-(1-7)-MAS axis, thus failed to identify the hypotheses that the increase in tissue ACE2-Ang-(1-7)MAS will result in increased circulating ACE2-Ang-(1-7)MAS activities. Moreover, the mechanisms of ACE2 that regulate $\mathrm{CHD}$ in humans needs to be further determined via basic research.
In conclusion, the present study provided novel information on ACE2-Ang-(1-7)-MAS axis in CHD. Curating ACE2 levels, but not Ang-(1-7) and Ang-(1-9) levels, significantly increased in female CHD group compared with non-CHD group, with subgroup analysis showing that the significant difference only exists in patients with multi-vessel lesions. The increased ACE2 was independently associated with CHD in female after adjusting for the confounding factors. Our findings support that the circulating ACE2 level may be a potential biomarker of CHD with its direct cardiovascular protection, thus modulation of ACE2 could offer a future therapeutic option in patients with atherosclerotic disease.

Acknowledgements The authors thank Mr. Xiangfeng Dou (Department of Epidemiology, Beijing Center for Disease Prevention and Control, Beijing 100013, PR China) for his help in statistical analysis.

Funding This work was supported by National Natural Science Foundation of China [Grant numbers 81273599, 81770253]; Guangdong Natural Science Foundation [Grant number 2015A030313661] and the Science and Technology Planning Project of Guangdong Province [Grant number 2014A020212404].

\section{Compliance with ethical standards}

Conflict of interest The authors have no conflicts of interest to disclose.

Human and animal rights statement The authors declare all human studies have been approved by the appropriate ethics committee and have, therefore, been performed in accordance with the ethical standards laid down in the 1964 Declaration of Helsinki and its later amendments. This article does not contain any studies with animals performed by any of the authors. All persons gave their informed consent prior to their inclusion in the study.

\section{References}

1. Chappell MC (2012) Nonclassical renin-angiotensin system and renal function. Compr Physiol 2(4):2733-2752

2. Patel SK, Velkoska E, Burrell LM (2013) Emerging markers in cardiovascular disease: where does angiotensin-converting enzyme 2 fit in? Clin Exp Pharmacol Physiol 40(8):551-559

3. Mehta PK, Griendling KK (2007) Angiotensin II cell signaling: physiological and pathological effects in the cardiovascular system. Am J Physiol Cell Physiol 292(1):C82-97

4. Donoghue M, Hsieh F, Baronas E, Godbout K, Gosselin M, Stagliano N, Donovan M, Woolf B, Robison K, Jeyaseelan R, Breitbart RE, Acton S (2000) a novel angiotensin-converting enzyme-related carboxypeptidase (ACE2) converts angiotensin I to angiotensin 1-9. Circ Res 87(5):e1-e9

5. Tipnis SR, Hooper NM, Hyde R, Karran E, Christie G, Turner AJ (2000) A human homolog of angiotensin-converting enzyme. Cloning and functional expression as a captopril-insensitive carboxypeptidase. J Biol Chem 275(43):33238-33243

6. Santos RA, Simoes e Silva AC, Maric C, Silva DM, Machado RP, de Buhr I, Heringer-Walther S, Pinheiro SV, Lopes MT, Bader M, Mendes EP, Lemos VS, Campagnole-Santos MJ, Schultheiss HP, 
Speth R, Walther T (2003) Angiotensin-(1-7) is an endogenous ligand for the $\mathrm{G}$ protein-coupled receptor Mas. Proc Natl Acad Sci USA 100(14):8258-8263

7. Varagic J, Ahmad S, Nagata S, Ferrario CM (2014) ACE2: angiotensin II/angiotensin-(1-7) balance in cardiac and renal injury. Curr Hypertens Rep 16(3):420

8. Mercure C, Yogi A, Callera GE, Aranha AB, Bader M, Ferreira AJ, Santos RA, Walther T, Touyz RM, Reudelhuber TL (2008) Angiotensin(1-7) blunts hypertensive cardiac remodeling by a direct effect on the heart. Circ Res 103(11):1319-1326

9. Patel VB, Parajuli N, Oudit GY (2014) Role of angiotensin-converting enzyme 2 (ACE2) in diabetic cardiovascular complications. Clin Sci (Lond) 126(7):471-482

10. Ocaranza MP, Lavandero S, Jalil JE, Moya J, Pinto M, Novoa U, Apablaza F, Gonzalez L, Hernandez C, Varas M, Lopez R, Godoy I, Verdejo H, Chiong M (2010) Angiotensin-(1-9) regulates cardiac hypertrophy in vivo and in vitro. J Hypertens 28(5):1054-1064

11. Flores-Munoz M, Work LM, Douglas K, Denby L, Dominiczak AF, Graham D, Nicklin SA (2012) Angiotensin-(1-9) attenuates cardiac fibrosis in the stroke-prone spontaneously hypertensive rat via the angiotensin type 2 receptor. Hypertension 59(2):300-307

12. Sluimer JC, Gasc JM, Hamming I, van Goor H, Michaud A, van den Akker LH, Jutten B, Cleutjens J, Bijnens AP, Corvol P, Daemen MJ, Heeneman S (2008) Angiotensin-converting enzyme 2 (ACE2) expression and activity in human carotid atherosclerotic lesions. J Pathol 215(3):273-279

13. Zhang YH, Hao QQ, Wang XY, Chen X, Wang N, Zhu L, Li SY, Yu QT, Dong B (2015) ACE2 activity was increased in atherosclerotic plaque by losartan: Possible relation to anti-atherosclerosis. J Renin Angiotensin Aldosterone Syst 16(2):292-300

14. Zhang YH, Zhang YH, Dong XF, Hao QQ, Zhou XM, Yu QT, Li SY, Chen X, Tengbeh AF, Dong B, Zhang Y (2015) ACE2 and Ang-(1-7) protect endothelial cell function and prevent early atherosclerosis by inhibiting inflammatory response. Inflamm Res 64(3-4):253-260

15. Zhang C, Zhao YX, Zhang YH, Zhu L, Deng BP, Zhou ZL, Li SY, Lu XT, Song LL, Lei XM, Tang WB, Wang N, Pan CM, Song HD, Liu CX, Dong B, Zhang Y, Cao Y (2010) Angiotensin-converting enzyme 2 attenuates atherosclerotic lesions by targeting vascular cells. Proc Natl Acad Sci USA 107(36):15886-15891

16. Dong B, Zhang C, Feng JB, Zhao YX, Li SY, Yang YP, Dong QL, Deng BP, Zhu L, Yu QT, Liu CX, Liu B, Pan CM, Song HD, Zhang MX, Zhang Y (2008) Overexpression of ACE2 enhances plaque stability in a rabbit model of atherosclerosis. Arterioscler Thromb Vasc Biol 28(7):1270-1276

17. Thomas MC, Pickering RJ, Tsorotes D, Koitka A, Sheehy K, Bernardi S, Toffoli B, Nguyen-Huu TP, Head GA, Fu Y, Chin-Dusting J, Cooper ME, Tikellis C (2010) Genetic Ace2 deficiency accentuates vascular inflammation and atherosclerosis in the ApoE knockout mouse. Circ Res 107(7):888-897

18. Yang J, Yang X, Meng X, Dong M, Guo T, Kong J, Zhang K, Zhang Y, Zhang C (2015) Endogenous activated angiotensin-(1-7) plays a protective effect against atherosclerotic plaques unstability in high fat diet fed ApoE knockout mice. Int J Cardiol 184:645-652

19. Tesanovic S, Vinh A, Gaspari TA, Casley D, Widdop RE (2010) Vasoprotective and atheroprotective effects of angiotensin (1-7) in apolipoprotein E-deficient mice. Arterioscler Thromb Vasc Biol 30(8):1606-1613

20. Yang JM, Dong M, Meng X, Zhao YX, Yang XY, Liu XL, Hao PP, Li JJ, Wang XP, Zhang K, Gao F, Zhao XQ, Zhang MX, Zhang Y, Zhang C (2013) Angiotensin-(1-7) dose-dependently inhibits atherosclerotic lesion formation and enhances plaque stability by targeting vascular cells. Arterioscler Thromb Vasc Biol 33(8):1978-1985
21. Head SJ, Farooq V, Serruys PW, Kappetein AP (2014) The SYNTAX score and its clinical implications. Heart 100(2):169-177

22. Abdella NA (2002) Controversies in management of diabetes in patients with coronary heart disease. Med Princ Pract 11(Suppl 2):69-74

23. Akishita M, Fukai S, Hashimoto M, Kameyama Y, Nomura K, Nakamura T, Ogawa S, Iijima K, Eto M, Ouchi Y (2010) Association of low testosterone with metabolic syndrome and its components in middle-aged Japanese men. Hypertens Res 33(6):587-591

24. Authors/Task Force members, Windecker S, Kolh P, Alfonso F, Collet JP, Cremer J, Falk V, Filippatos G, Hamm C, Head SJ, Juni P, Kappetein AP, Kastrati A, Knuuti J, Landmesser U, Laufer G, Neumann FJ, Richter DJ, Schauerte P, Sousa Uva M, Stefanini GG, Taggart DP, Torracca L, Valgimigli M, Wijns W, Witkowski A (2014) 2014 ESC/EACTS Guidelines on myocardial revascularization: the task force on myocardial revascularization of the european society of cardiology (ESC) and the European Association for Cardio-Thoracic Surgery (EACTS) developed with the special contribution of the European Association of Percutaneous Cardiovascular Interventions (EAPCI). Eur Heart J 35(37):2541-2619

25. Amsterdam EA, Wenger NK, Brindis RG, Casey DE Jr, Ganiats TG, Holmes DR Jr, Jaffe AS, Jneid H, Kelly RF, Kontos MC, Levine GN, Liebson PR, Mukherjee D, Peterson ED, Sabatine MS, Smalling RW, Zieman SJ, Members AATF (2014) 2014 AHA/ACC guideline for the management of patients with nonST-elevation acute coronary syndromes: a report of the American College of Cardiology/American Heart Association Task Force on Practice Guidelines. Circulation 130(25):e344-426

26. Soro-Paavonen A, Gordin D, Forsblom C, Rosengard-Barlund M, Waden J, Thorn L, Sandholm N, Thomas MC, Groop PH, FinnDiane Study G (2012) Circulating ACE2 activity is increased in patients with type 1 diabetes and vascular complications. J Hypertens 30(2):375-383

27. Roberts MA, Velkoska E, Ierino FL, Burrell LM (2013) Angiotensin-converting enzyme 2 activity in patients with chronic kidney disease. Nephrol Dial Transpl 28(9):2287-2294

28. Sullivan JC, Bhatia K, Yamamoto T, Elmarakby AA (2010) Angiotensin (1-7) receptor antagonism equalizes angiotensin IIinduced hypertension in male and female spontaneously hypertensive rats. Hypertension 56(4):658-666

29. Zimmerman MA, Harris RA, Sullivan JC (2014) Female spontaneously hypertensive rats are more dependent on ANG (1-7) to mediate effects of low-dose AT1 receptor blockade than males. Am J Physiol Renal Physiol 306(10):F1136-1142

30. Sullivan JC, Rodriguez-Miguelez P, Zimmerman MA, Harris RA (2015) Differences in angiotensin (1-7) between men and women. Am J Physiol Heart Circ Physiol 308(9):H1171-1176

31. Reyes-Engel A, Morcillo L, Aranda FJ, Ruiz M, Gaitan MJ, Mayor-Olea A, Aranda P, Ferrario CM (2006) Influence of gender and genetic variability on plasma angiotensin peptides. J Renin Angiotensin Aldosterone Syst 7(2):92-97

32. Bukowska A, Spiller L, Wolke C, Lendeckel U, Weinert S, Hoffmann J, Bornfleth P, Kutschka I, Gardemann A, Isermann B, Goette A (2017) Protective regulation of the ACE2/ACE gene expression by estrogen in human atrial tissue from elderly men. Exp Biol Med (Maywood) 242(14):1412-1423

33. Shenoy V, Grobe JL, Qi Y, Ferreira AJ, Fraga-Silva RA, Collamat G, Bruce E, Katovich MJ (2009) 17 $\beta$-Estradiol modulates local cardiac renin-angiotensin system to prevent cardiac remodeling in the DOCA-salt model of hypertension in rats. Peptides 30(12):2309-2315

34. Mompeón A, Lázaro-Franco M, Bueno-Betí C, Pérez-Cremades D, Vidal-Gómez X, Monsalve E, Gironacci MM, Hermenegildo C, Novella S (2016) Estradiol, acting through ER $\alpha$, induces endothelial non-classic renin-angiotensin system increasing angiotensin 1-7 production. Mol Cell Endocrinol 422:1-8 
35. Shaw LJ, Bairey Merz CN, Pepine CJ, Reis SE, Bittner V, Kelsey SF, Olson M, Johnson BD, Mankad S, Sharaf BL, Rogers WJ, Wessel TR, Arant CB, Pohost GM, Lerman A, Quyyumi AA, Sopko G, Investigators W (2006) Insights from the NHLBI-sponsored Women's Ischemia Syndrome Evaluation (WISE) study: part I: gender differences in traditional and novel risk factors, symptom evaluation, and gender-optimized diagnostic strategies. J Am Coll Cardiol 47(3 Suppl):S4-S20

36. Uri K, Fagyas M, Manyine Siket I, Kertesz A, Csanadi Z, Sandorfi G, Clemens M, Fedor R, Papp Z, Edes I, Toth A, Lizanecz $E$ (2014) New perspectives in the renin-angiotensin-aldosterone system (RAAS) IV: circulating ACE2 as a biomarker of systolic dysfunction in human hypertension and heart failure. PLOS ONE 9(4):e87845

37. Epelman S, Tang WHW, Chen SY, Van Lente F, Francis GS, Sen S (2008) Detection of soluble angiotensin-converting enzyme 2 in heart failure. J Am Coll Cardiol 52(9):750-754

38. Ocaranza MP, Godoy I, Jalil JE, Varas M, Collantes P, Pinto M, Roman M, Ramirez C, Copaja M, Diaz-Araya G, Castro P, Lavandero S (2006) Enalapril attenuates downregulation of Angiotensin-converting enzyme 2 in the late phase of ventricular dysfunction in myocardial infarcted rat. Hypertension 48(4):572-578

39. Zisman LS (2005) ACE and ACE2: a tale of two enzymes. Eur Heart J 26(4):322-324

40. Der Sarkissian S, Grobe JL, Yuan L, Narielwala DR, Walter GA, Katovich MJ, Raizada MK (2008) Cardiac overexpression of angiotensin converting enzyme 2 protects the heart from ischemiainduced pathophysiology. Hypertension 51(3):712-718

41. Flores-Monroy J, Ferrario CM, Valencia-Hernandez I, HernandezCampos ME, Martinez-Aguilar L (2014) Comparative effects of a novel angiotensin-converting enzyme inhibitor versus captopril on plasma angiotensins after myocardial infarction. Pharmacology 94(1-2):21-28

42. Burchill LJ, Velkoska E, Dean RG, Griggs K, Patel SK, Burrell LM (2012) Combination renin-angiotensin system blockade and angiotensin-converting enzyme 2 in experimental myocardial infarction: implications for future therapeutic directions. Clin Sci (Lond) 123(11):649-658

43. Ortiz Pérez JT, Riera M, Genover X, De Caralt T, Perea R, Pascual J, Romeo M (2011) Serum ACE2 activity correlates with infarct size and left ventricular dysfunction during acute myocardial infarction. J Cardiovasc Magn Reson 13(Suppl 1):P142

44. Liu W, Zhou X, Yu F, Hu J, Hu W (2013) Arg972 Insulin receptor substrate-1 is associated with decreased serum angiotensin-converting enzyme 2 levels in acute myocardial infarction patients: in vivo and in vitro evidence. Cardiovasc Diabetol 12:151
45. Ramchand J, Patel SK, Srivastava PM, Farouque O, Burrell LM (2018) Elevated plasma angiotensin converting enzyme 2 activity is an independent predictor of major adverse cardiac events in patients with obstructive coronary artery disease. PLoS ONE 13(6): 0198144

46. Lawton JS (2011) Sex and gender differences in coronary artery disease. Semin Thorac Cardiovasc Surg 23(2):126-130

47. Gylling H, Rajaratnam RA, Vartiainen E, Puska P, Miettinen TA (2006) Changes in serum level and metabolism of cholesterol with plant stanol esters in postmenopausal women with and without coronary artery disease. Menopause 13(2):286-293

48. Lambert DW, Yarski M, Warner FJ, Thornhill P, Parkin ET, Smith AI, Hooper NM, Turner AJ (2005) Tumor necrosis factor-alpha convertase (ADAM17) mediates regulated ectodomain shedding of the severe-acute respiratory syndrome-coronavirus (SARS$\mathrm{CoV}$ ) receptor, angiotensin-converting enzyme-2 (ACE2). J Biol Chem 280(34):30113-30119

49. Lely AT, Hamming I, van Goor H, Navis GJ (2004) Renal ACE2 expression in human kidney disease. J Pathol 204(5):587-593

50. Wysocki J, Batlle D (2013) Reduced plasma ACE2 activity in dialysis patients: another piece in the conundrum of factors involved in hypertension and cardiovascular morbidity? Nephrol Dial Transpl 28(9):2200-2202

51. Westermeier F, Bustamante M, Pavez M, Garcia L, Chiong M, Ocaranza MP, Lavandero S (2015) Novel players in cardioprotection: Insulin like growth factor-1, angiotensin-(1-7) and angiotensin-(1-9). Pharmacol Res 101:41-55

52. Wang J, He W, Guo L, Zhang Y, Li H, Han S, Shen D (2017) The ACE2-Ang (1-7)-Mas receptor axis attenuates cardiac remodeling and fibrosis in post-myocardial infarction. Mol Med Rep 16(2):1973-1981

53. Santos RAS, Sampaio WO, Alzamora AC, Motta-Santos D, Alenina N, Bader M, Campagnole-Santos MJ (2018) The ACE2/ angiotensin-(1-7)/MAS axis of the renin-angiotensin system: focus on angiotensin-(1-7). Physiol Rev 98(1):505-553

54. Li W, Li J, Hao P, Chen W, Meng X, Li H, Zhang Y, Zhang C, Yang J (2016) Imbalance between angiotensin II and angiotensin-(1-7) in human coronary atherosclerosis. J Renin Angiotensin Aldosterone Syst. https://doi.org/10.1177/1470320316659618

Publisher's Note Springer Nature remains neutral with regard to jurisdictional claims in published maps and institutional affiliations. 